\title{
Health Effects of Energy Resources
}

\section{Introduction}

Energy resources (coal, oil, and natural gas) are among the cornerstones of modern industrial society. The exploitation of these resources, however, is not without costs. Energy materials may contain harmful chemical substances that, if mobilized into air, water, or soil, can adversely impact human health and environmental quality. In order to address the issue of human exposure to toxic substances derived from energy resources, the U.S. Geological Survey (USGS) Energy Resources Program developed a project entitled "Impacts of Energy Resources on Human Health and Environmental Quality." The project is intended to provide policymakers and the public with the scientific information needed to weigh the human health and environmental consequences of meeting our energy needs. This fact sheet discusses several areas where the USGS Energy Resources Program is making scientific advances in this endeavor.

\section{Toxic Substances from Coal in Water Supplies}

Clean water is fundamentally important to human health, but the impact of toxic substances derived from energy resources (especially coal) in water supplies has received little attention. Organic and inorganic contaminants may be leached from coal, coal waste, or coal combustion products into surface or groundwater, or released in water from coalbed natural gas wells. In areas of the semiarid western United States, the local drinking-water supply consists of groundwater residing in or adjacent to coal beds. This situation poses a key question: Does the potential for natural leaching of toxic substances from coal into water supplies pose a threat to human health and the environment? The USGS is investigating this possible link in several places.

Balkan Endemic Nephropathy-One disease model of the health effects of toxic organic substances from coal in water supplies is Balkan endemic nephropathy (BEN). BEN, ultimately leading to kidney failure (fig. 1), occurs in clusters of rural villages in southeastern Europe (Serbia, Romania, Bulgaria, Bosnia, and Croatia). BEN patients also have a very high incidence of cancers of the renal pelvis and ureter. USGS scientists observed a spatial relationship between the locations of BEN villages and the distribution of lignite coal deposits. Here, wells and springs located downslope from coal deposits are the principal water supply. These observations led to the hypothesis that coal-derived contaminants in the drinking-water supply could be responsible for the occurrence of BEN.

Further study by the USGS and medical collaborators has shown that the well and spring water from BEN villages

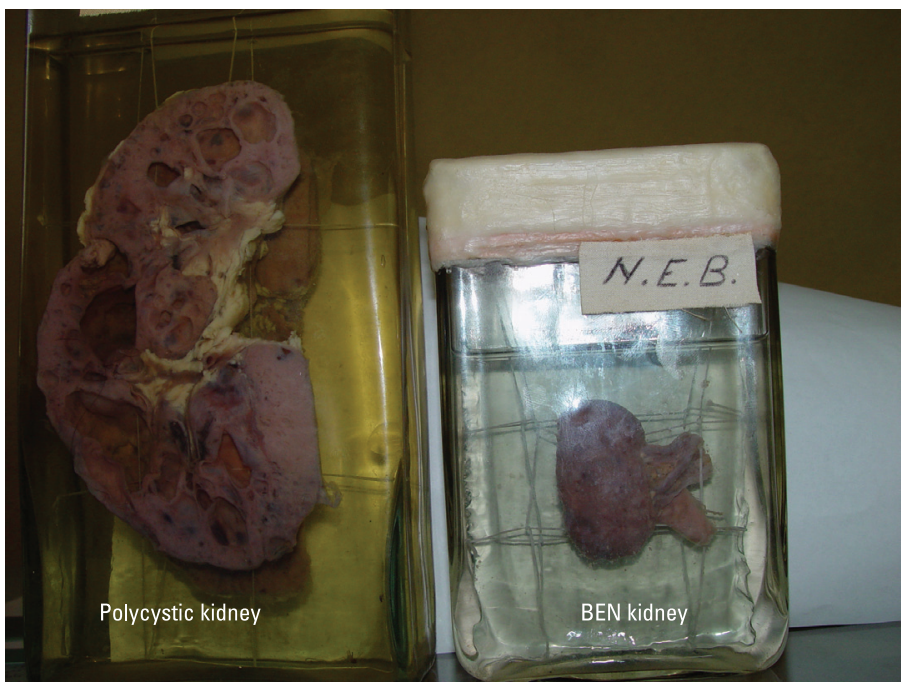

Figure 1. A picture of a polycystic kidney (left) and a kidney from a patient who died of BEN. The BEN kidney is one third normal size and kidney failure had occurred. The treatment options for BEN are long-term dialysis or kidney transplantation.

contains higher concentrations of coal-derived organic substances, compared to well and spring water from non-BEN villages in the affected countries (fig. 2). Potentially toxic organic compounds identified in the water from BEN villages include aromatic amines, heterocyclic compounds, and terpenoids. These classes of organic compounds are known to cause kidney disease and cancer. Long-term (more than 20 years) use and exposure to the contaminated water in BEN villages, in combination with genetic factors and other environmental co-factors, are hypothesized to produce BEN in the local population.

Toxicology studies by USGS scientists and collaborators demonstrate that human kidney cells exposed to organic compounds isolated from BEN village water supplies exhibit significant cellular changes and cell death, relative to controls (fig. 3). USGS scientists are collaborating with medical doctors to continue research on possible environmental causes of BEN in countries with incidences of this disease.

Panendemic Nephropathy - The apparent linkage between the occurrence of BEN, low-rank coal, and the use of untreated well water led to the following question: Do diseases similar to BEN occur elsewhere? Untreated drinkingwater supplies occur in proximity to low-rank coal deposits in numerous locations worldwide. USGS scientists and medical collaborators use the term "Panendemic Nephropathy" (PEN) to describe diseases with characteristics similar to BEN that 
occur outside of the Balkans. U.S. States with a high incidence of cancers of the renal pelvis (similar to the cancers linked to BEN) include Wyoming, North Dakota, South Dakota, and Louisiana. These States have extensive low-rank coal deposits and large rural populations that use untreated well water. In some areas of these States, coal deposits serve as aquifers for water supply.

In northwestern Louisiana, USGS work has demonstrated the presence of potentially toxic organic compounds in drinking-water wells penetrating coal-bearing rocks, while well water from sites outside of the coal area do not contain these compounds (fig. 4). This region has the highest incidence of cancers of the renal pelvis in Louisiana. The types of organic compounds observed in drinking-water supplies in coal-bearing areas of northwestern Louisiana are similar to those observed in well water from BEN areas. Ongoing geochemical and collaborative medical studies will help determine if PEN occurs in northwestern Louisiana. Similar studies of PEN are being conducted in Texas, Wyoming, and North Dakota.

\section{Produced Water from Coalbed Natural Gas}

Production-Natural gas from coal, referred to as coalbed natural gas $(\mathrm{CBNG})$, is a significant energy resource in the United States (about 10\% of total natural gas production). Production of CBNG requires removing water from the coalbed to depressurize and allow gas to be released from the coal. About 1.3 trillion gallons of so-called produced water is withdrawn annually from the major CBNG basins in the United States.

The disposal of large volumes of produced water of varying quality is one of the most important environmental issues surrounding the development of the CBNG resource. Research on the environmental impacts of produced water has focused primarily on the effects of inorganic dissolved solids and salts. Based on studies of BEN and PEN, the USGS undertook an examination of organic compounds present in produced water, with initial work conducted in the Powder River Basin, Wyo. Potentially toxic organic substances detected in the produced water included polycyclic aromatic hydrocarbons (PAHs), aromatic amines, heterocyclic compounds, and terpenoids. Concentrations of all of these compounds are typically low (micrograms per liter, $\mu \mathrm{g} / \mathrm{L}$ ), but human and animal health and environmental effects of chronic, long-term exposure to these low concentrations are unknown.

Coal Slurry - Coal slurry is a black suspension produced from the washing of coal (with water and chemicals) after mining. Washing is intended to remove sulfur, mineral matter, and fine particles from the coal prior to shipment to the end user. Coal slurry is usually pumped to surface impoundments or into abandoned underground mines for long-term storage. Approximately 1,000 slurry impoundments are located in the coal-mining areas of the Appalachian Basin (fig. 5), each containing from tens of thousands to billions of gallons of coal slurry.

A potential concern with coal-slurry impoundments is contamination of surface and groundwater with toxic organic and inorganic substances from the coal slurry. Toxic substances could originate from the coal and coal matrix, from chemicals added in the coal-washing process (kerosene and fuel oil) or chemicals added to promote coagulation of coal slurry (polyacrylamide). Little is known about the chemistry of coal

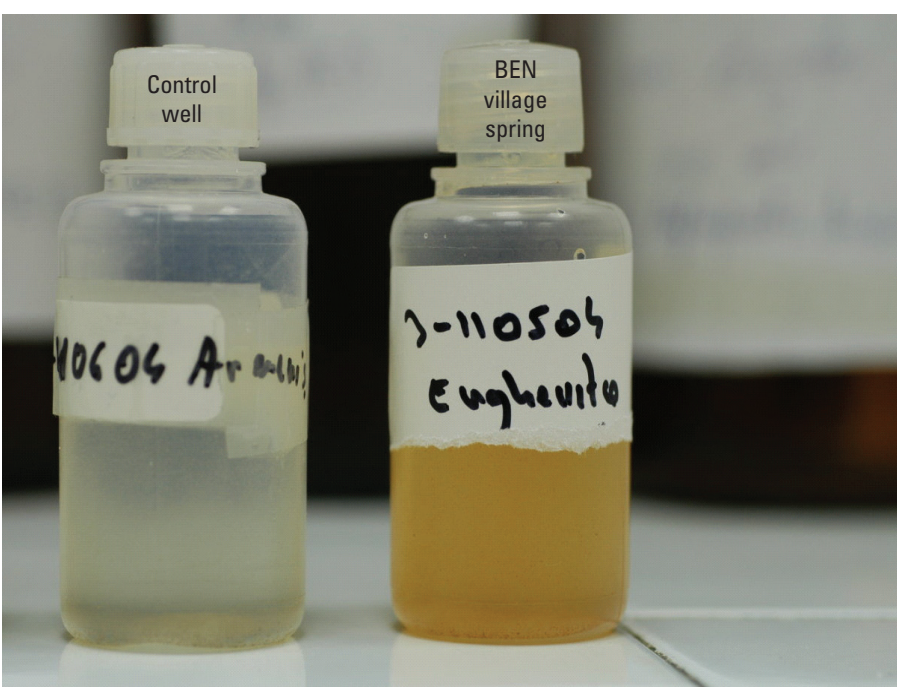

Figure 2. Dissolved organic substances isolated from drinking water in a BEN village (right) and a non-BEN control village (left). Note the much darker color in the water from the BEN village, indicative of the presence of organic substances.
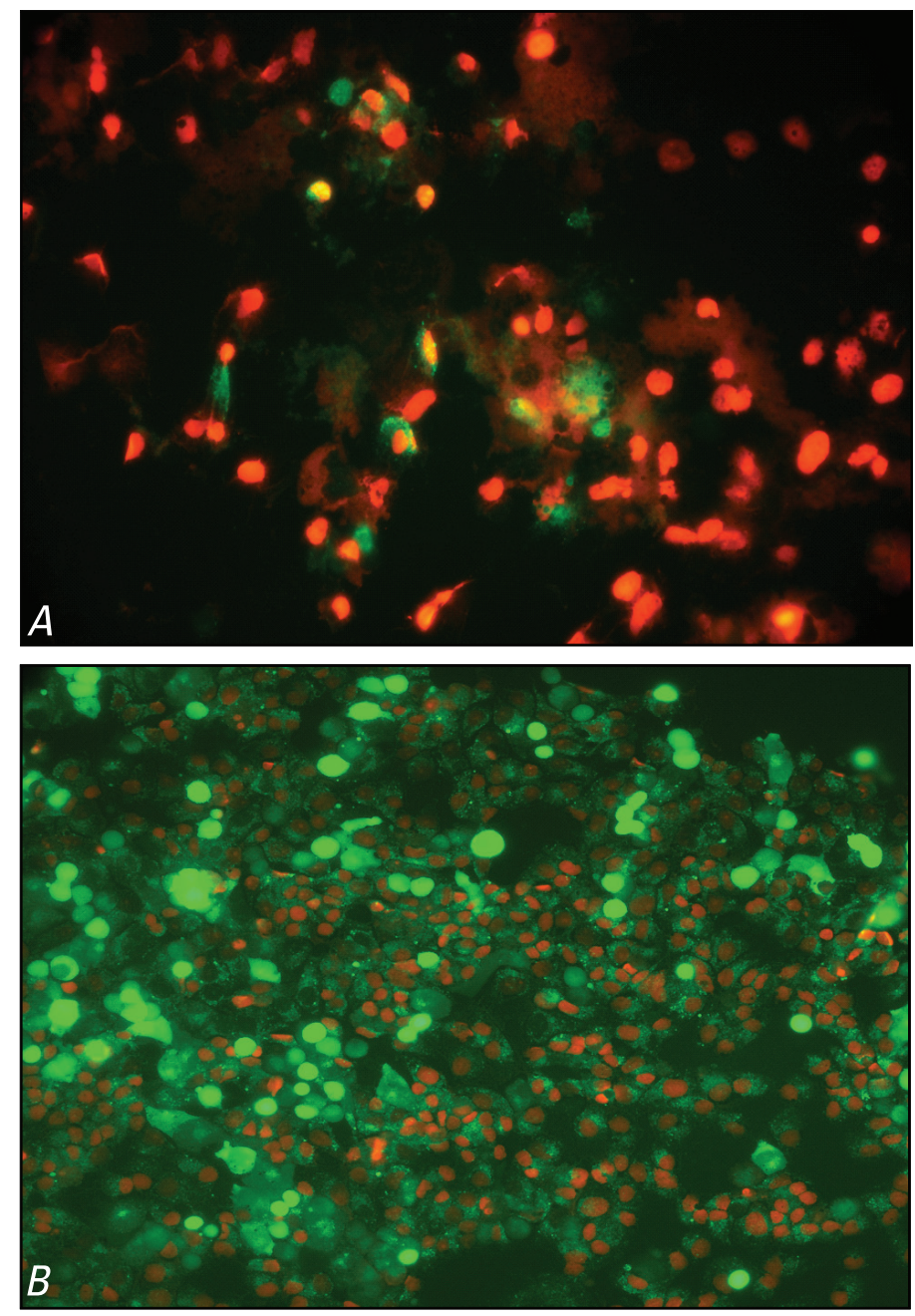

Figure 3. Magnification (200x) of human kidney cells exposed to organic material isolated from water from a BEN village well (top), and from a non-BEN control well (bottom). The red color staining in the cells treated with the BEN water indicates damage from loss of cell membrane integrity caused by the organic substances. 


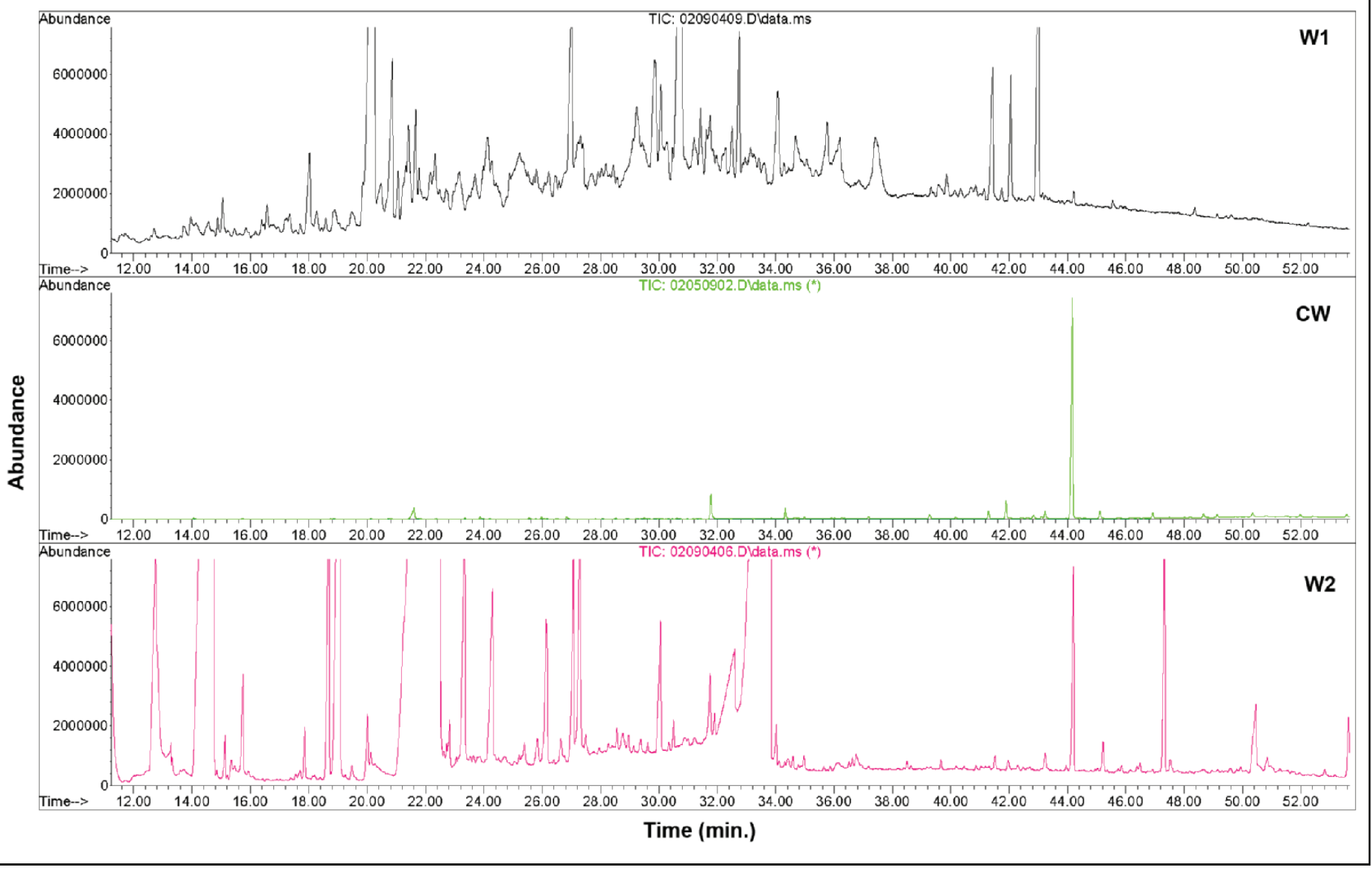

Figure 4. Scan showing organic compounds in water-supply wells penetrating a coal seam in northwestern Louisiana (W1 and W2), and from a control well. The W1 and W2 water samples are from an area with high rates of renal/pelvic cancers.

slurry, contamination of surface and groundwater by chemical substances from coal slurry, or human health and environmental issues linked to coal slurry. Citizen groups are becoming increasingly concerned about potential health hazards from coal-slurry impoundments. USGS scientists are participating with universities, State, and other Federal agencies in initiating studies of the chemistry and of potential human health and environmental impacts of coal slurry.

\section{Toxic Substances In Energy Combustion Products}

Toxic organic and inorganic byproducts of fuel combustion are responsible for demonstrated and potential health impacts in the United States and in many parts of world. In some cases, the link is well established, and in other cases, conditions are conducive to health impacts. Priorities for this research include (1) quantifying exposure levels and health effects of energy combustion products; (2) where possible, relating these results to applicable health standards; and (3) using these results to indicate a potential for toxicity.

$\mathbf{P M}_{2.5}$ - The presence in air of fine particulate matter $<2.5$ micrometers in size $(<0.0001$ inches $)$, called $\mathrm{PM}_{2.5}$, and originating from coal combustion and other sources, is a serious health concern. This material is small enough to be readily lodged in small interstices (alveoli) in the lungs. The U.S. Environmental Protection Agency (USEPA) air-quality regulatory standards are based on limits in the amount of $\mathrm{PM}_{2.5}$

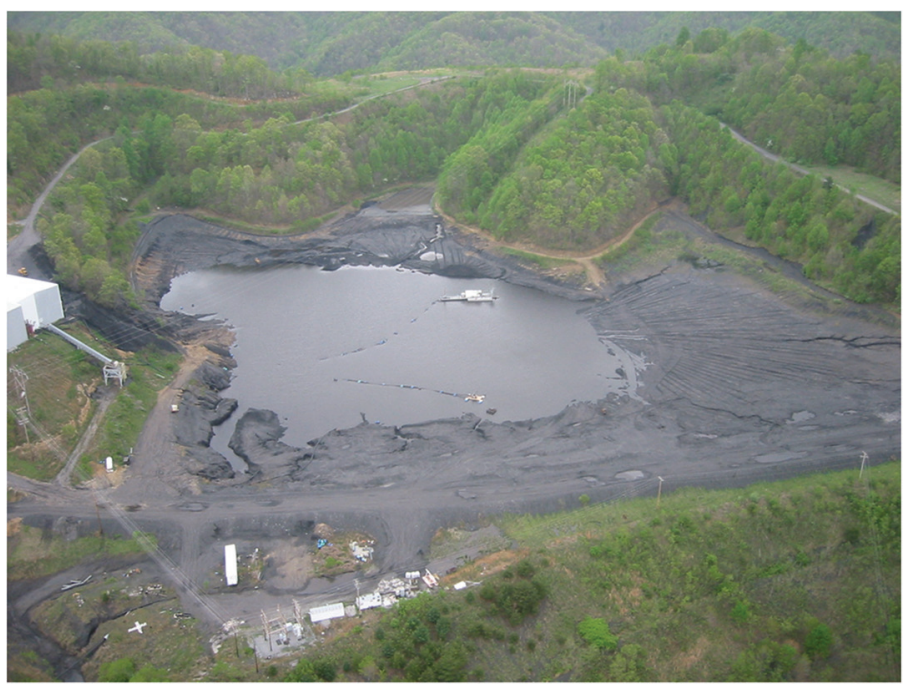

Figure 5. Photo of a coal-slurry impoundment in the Appalachian Basin. (Photo courtesy of Ben Stout, Wheeling Jesuit University, Wheeling, W. Va.) 

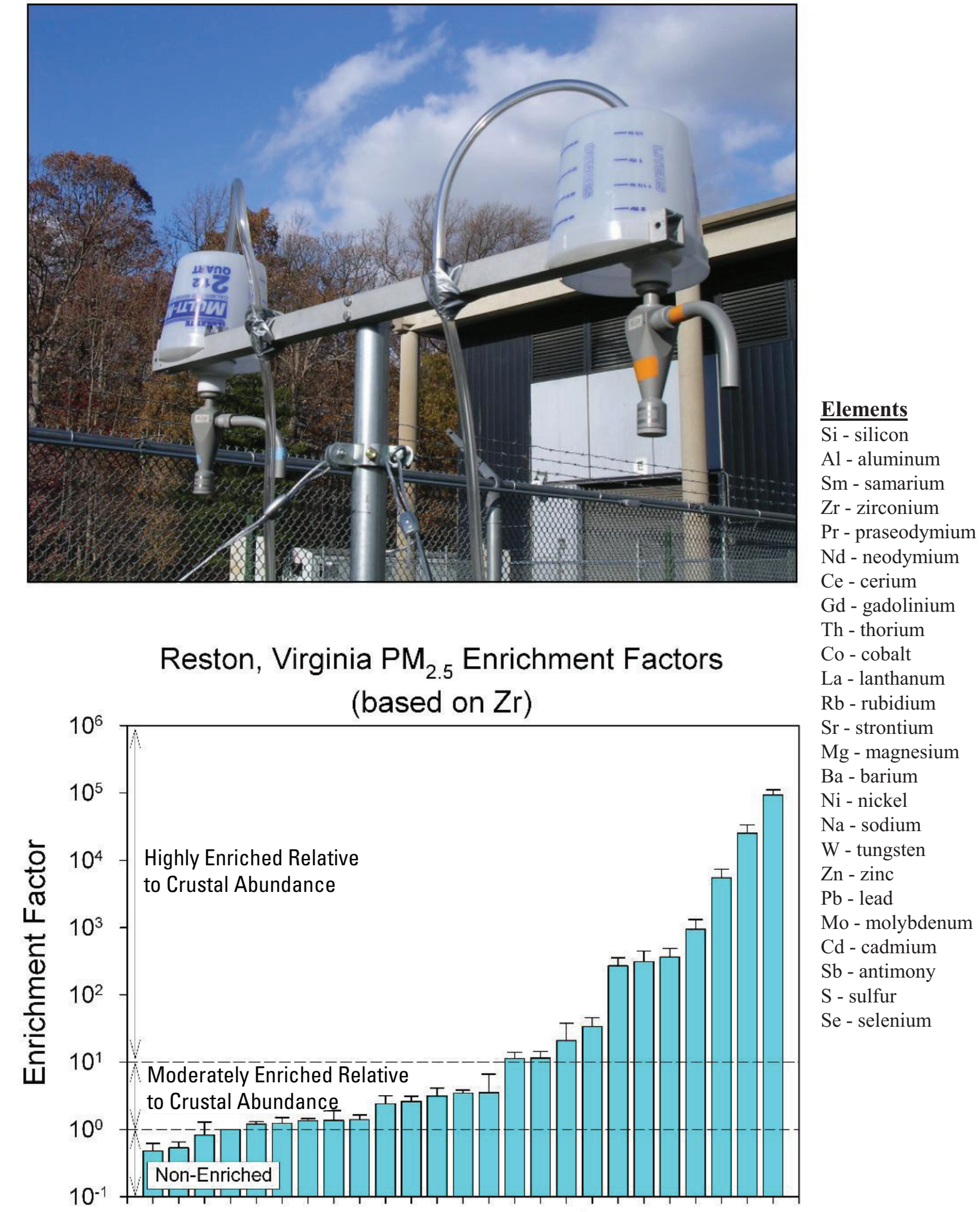

Figure 6. Sampling (upper) and results (lower) for ambient $\mathrm{PM}_{2.5}$ adjacent to a steam boiler plant in northern Virginia. Large enrichment factors for antimony, sulfur, and selenium, relative to average abundance in the Earth's crust, are indicative of a coal combustion signal. Similarly, enrichment in zinc, lead, and cadmium can be attributed to brake dust and other vehicle-related processes.

\section{Elements}

$\mathrm{Si}$ - silicon

$\mathrm{Al}$ - aluminum

Sm - samarium

$\mathrm{Zr}$ - zirconium

Pr - praseodymium

$\mathrm{Nd}$ - neodymium

$\mathrm{Ce}$ - cerium

Gd - gadolinium

Th - thorium

Co - cobalt

anthanum

$\mathrm{Mg}$ - magnesium

$\mathrm{Ba}$ - barium

Mo - molybdenum

$\mathrm{Cd}$ - cadmium

$\mathrm{Sb}$ - antimony

$\mathrm{S}$ - sulfur

Se - selenium 


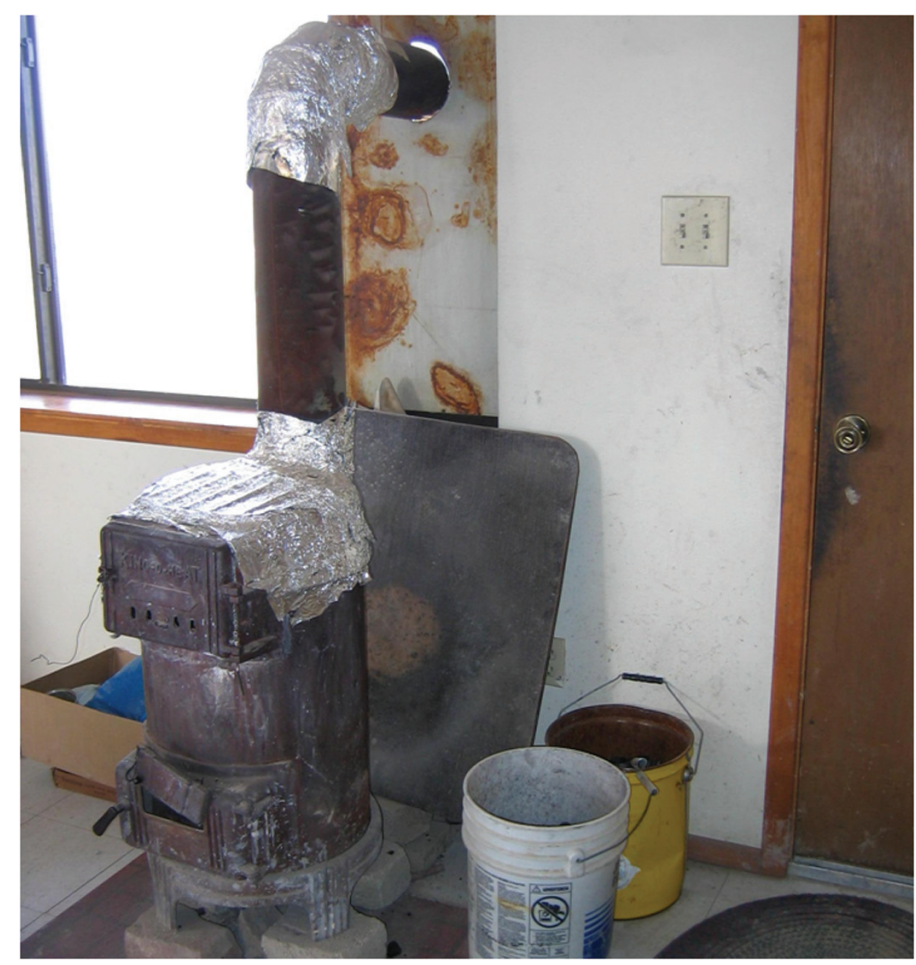

Figure 7. Coal-burning stove inside household, Navajo Nation, New Mexico.

in a volume of air averaged over time (periods of 24 hours or a year). The USEPA estimates that meeting its nationwide $\mathrm{PM}_{2.5}$ standards will prevent thousands of premature deaths in people with heart and lung disease, with corresponding reductions in hospital admissions for respiratory and cardiovascular diseases (USEPA, 2007).

USGS studies complement $\mathrm{PM}_{2.5}$ air-quality monitoring by emphasizing detailed chemical, mineralogical, and surface characteristics, including information on potentially toxic metals and organic compounds, which may be leachable in the lungs (fig. 6). Knowledge of specific $\mathrm{PM}_{2.5}$ characteristics is also important in determining sources of $\mathrm{PM}_{2.5}$. Studies are focused on specific instances where epidemiological data suggest respiratory disease is linked to energy combustion processes.

Navajo Nation-A multi-agency study in the Navajo Nation of New Mexico focuses on the extent of human exposure to contaminants in particulate matter derived from domestic coal combustion and links to respiratory disease. The approach involves the following: (1) examining respiratory health data; (2) collecting information on the type and condition of coal-burning stoves, plus sampling coal used domestically; and (3) measuring indoor and outdoor air quality, including $\mathrm{PM}_{2.5}$. Results of the study will assist tribal authorities in implementing policies or practices that improve the health of tribal residents who use coal as an energy source (fig. 7).

Measurements of $\mathrm{PM}_{2.5}$ concentrations in the Navajo Nation show that in winter, when coal stoves are in use, some homes exceed the USEPA 24-hour ambient (outdoor) $\mathrm{PM}_{2.5}$ standard. Analysis of $\mathrm{PM}_{2.5}$ samples from Navajo homes burning coal shows an abundance of organic compounds indicative of a coal source. The potential toxicity of these compounds is being investigated in ongoing toxicology studies.

\section{Toxicology}

Toxicology is the study of the effects of harmful (toxic) substances in the environment on the human body. Toxicology provides the critical link between the identification of a chemical in the environment and the effect of the chemical on living things, including humans. Toxicology can involve exposure of cell cultures or animals that may mimic human responses (animal models) to suspected toxins in the environment.

To enhance our understanding of the impact of energy resources on human health, the USGS has developed a toxicology lab. This facility is used to conduct experiments that expose human cells (kidney, liver, lung, etc.) to energy-derived toxins in water and air and to examine the effects of these toxins on cells (fig. 3). USGS studies in toxicology employ sophisticated molecular biological techniques to examine the mechanisms by which chemical substances exert toxic effects on human cells (for example, formation of DNA adducts). The toxicology lab also cooperates with biomedical research collaborators on human-cell experiments, on toxicology studies of human-enzyme systems, and in animal model studies.

\section{Reference Cited}

U.S. Environmental Protection Agency, 2007, Particulate matter: U.S. Environmental Protection Agency, available online at http://www.epa.gov/air/particlepollution/index.html. (Accessed August 13, 2007.)

\section{By William Orem, ${ }^{1}$ Calin Tatu, ${ }^{2}$ Nikola Pavlovic, ${ }^{3}$ Joseph Bunnell, ${ }^{1}$ Allan Kolker, ${ }^{1}$ Mark Engle, ${ }^{1}$ and Ben Stout ${ }^{4}$}

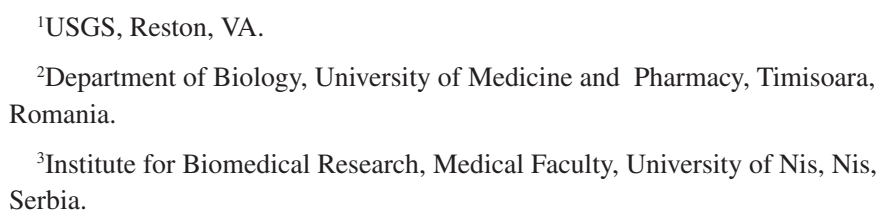
Serbia.

${ }^{4}$ Dept. of Biology, Wheeling Jesuit University, Wheeling, WV.

\section{For more information, please contact:}

William Orem

U.S. Geological Survey

12201 Sunrise Valley Drive, MS 956

Reston, VA 20192

E-mail: borem@usgs.gov 